\title{
Lateral Earth Pressure behind Walls Rotating about Base considering Arching Effects
}

\author{
Dong Li, Wei Wang, and Qichang Zhang \\ Tianjin Key Laboratory of Nonlinear Dynamics and Chaos Control, School of Mechanical, Tianjin University, Tianjin 300072, China \\ Correspondence should be addressed to Qichang Zhang; qzhang@tju.edu.cn
}

Received 2 July 2014; Revised 20 August 2014; Accepted 8 September 2014; Published 11 November 2014

Academic Editor: Limin Sun

Copyright (C) 2014 Dong Li et al. This is an open access article distributed under the Creative Commons Attribution License, which permits unrestricted use, distribution, and reproduction in any medium, provided the original work is properly cited.

\begin{abstract}
In field, the earth pressure on a retaining wall is the common effect of kinds of factors. To figure out how key factors act, it has taken into account the arching effects together with the contribution from the mode of displacement of a wall to calculate earth pressure in the proposed method. Based on Mohr circle, a conversion factor is introduced to determine the shear stresses between artificial slices in soil mass. In the light of this basis, a modified differential slices solution is presented for calculation of active earth pressure on a retaining wall. Comparisons show that the result of proposed method is identical to observations from model tests in prediction of lateral pressures for walls rotating about the base.
\end{abstract}

\section{Introduction}

Prediction of earth pressure is an important subject of research for design of retaining structures in prone rupture region. Rupture mechanism in the backfill behind a retaining structure should take into account the mode of wall movement. It is common in practice that movements of retaining wall are considered in terms of translation $(\mathrm{T})$, rotation about base (RB), and rotation about top (RT). Conventional earth pressure theories are brought forward only for retaining structures with rigid free translation, such as methods modeled by Coulomb [1], Rankine [2], Khajehzadeh et al. [3], Xu [4], and differential slice technique Wang [5]. In contrast to the usual methods, the research needs more light on prediction of lateral earth pressure on a rotating wall. Terzaghi [6] conducted several large-scale model tests to recognize the importance of walls rotation. Despite the fail in measuring the actual stresses against the wall, he arrived at his conclusions by measuring the total thrust by load cells. Some researches applied pseudodynamic method to analyze the pressure on the retaining wall, such as [7-10]. However, all of them failed to take into account the arching effects in the soil. James and Bransby [11] investigated the passive failure of an initially vertical plane which was rotated about its base into a mass of dry sand with an unloaded horizontal surface. Although the results showed uniformity between the predicted principal compressive stress directions and the observed principal compressive strain increment direction, this theory only focuses on the failure mechanism of slipping plane and ignores other boundary conditions. Small-scale model of retaining walls (e.g., $[12,13])$ and field observations [14] have enhanced the understanding of lateral earth pressure problems of rotation. Chang used a modified Coulomb's solution of active pressure to analyze the earth pressure distribution due to different wall movements [15]. Recently, Song and Zhang [16] revealed the formation mechanism of earth pressures against rigid retaining wall with $\mathrm{RT}$ and $\mathrm{RB}$ mode. Nevertheless, soil arching effects should be taken into account to predict earth pressure distributions for application of advanced developments.

Granular matters exhibit some unique character, such as arching effects, which inspire the interest of a lot of scholars [17-20]. Soil arching behavior develops when the earth pressure transfers from the yielding part of soil to the adjacent part. Terzaghi [21] used trap door tests to explain how pressure transferred from yielding parts of a soil mass to adjoined stationary; nonyielding parts led to the formation of an arching zone. Following this pioneering study, numerous works have been carried out to investigate the arching effect in various engineering problems. Handy [22] deduced the 
distribution of lateral earth pressure behind a retaining wall by assuming that the curve describing the minor principal stress is a catenary. Later, Harrop-Williams [23] theoretically derived that the shape of the arch can be approximated by a circular arc to cohere with the assumption of constant stresses along the arch. Paik and Salgado [24] proposed a new formulation for calculating the active earth pressure on a rigid retaining wall undergoing horizontal translation, which took into account the arching effects that occurred in the retained soil mass. Jiang et al. [25] theoretically analyzed the shape of the minor principal stress arch. Using finite element method, Potts and Zdravkovic [26] reviewed the nature of the soil arching that developed in the retained soil mass. Nadukuru and Michalowski [27] applied discrete element method for calculation of active loads on retaining structures with different movements. The results showed that arching and modes of wall movements appear to be the primary cause affecting the pressure distribution.

Motivated by the above literature review, this paper focuses on an analytical method for the earth pressure distribution on a rigid wall rotating about base (RB) with consideration of the arching effects. First, it infers suitable lateral earth coefficients $K$ assuming that the arch forms a part of circular arc in the soil. Then using differential slice technique as the framework of analysis, a reasonable formula is proposed for RB. It adopts a simple concept of average friction angle of soil to relate the mobilized shearing resistance to wall displacement. At last, comparisons are made between the prediction of proposed method and existing experiments results.

\section{Basic Theory}

As Terzaghi alluded, arching may play a role in distribution of pressures on retaining structures. Whereas the term arching has been accepted in the geotechnical literature, the concept does not relate to the formation of a physical arch but rather a distribution of pressures for which stiffer components of the system attract more loads. According to Terzaghi's theory, a column of soil is assumed to move downwards under the influence of its own weight and is restrained by friction along the boundary of this falling column and the surrounding soil mass. In a similar way to Handy's method, it is to substitute a circular arc describing the path of the minor principal stress to mimic soil arching effects [24].

\section{Lateral Earth Pressure of Coefficients}

The following process is assumed: when the rotation is small, a similar deformation pattern characterized by quasi-rupture surfaces will uniformly distribute in the zone that has not yet run up to the limiting condition but with the shearing resistance only partly activated along these planes, as well as along the soil-wall interface in the same zone. With reference to walls rotating about base, an earlier discussion has indicated that rupture surfaces appear gradually from the upper part of the wall to the base. Figure 1 shows the condition behind a retaining wall after vertical settling of the fill occurs due to the wall movement. For portion of the wall, the shear

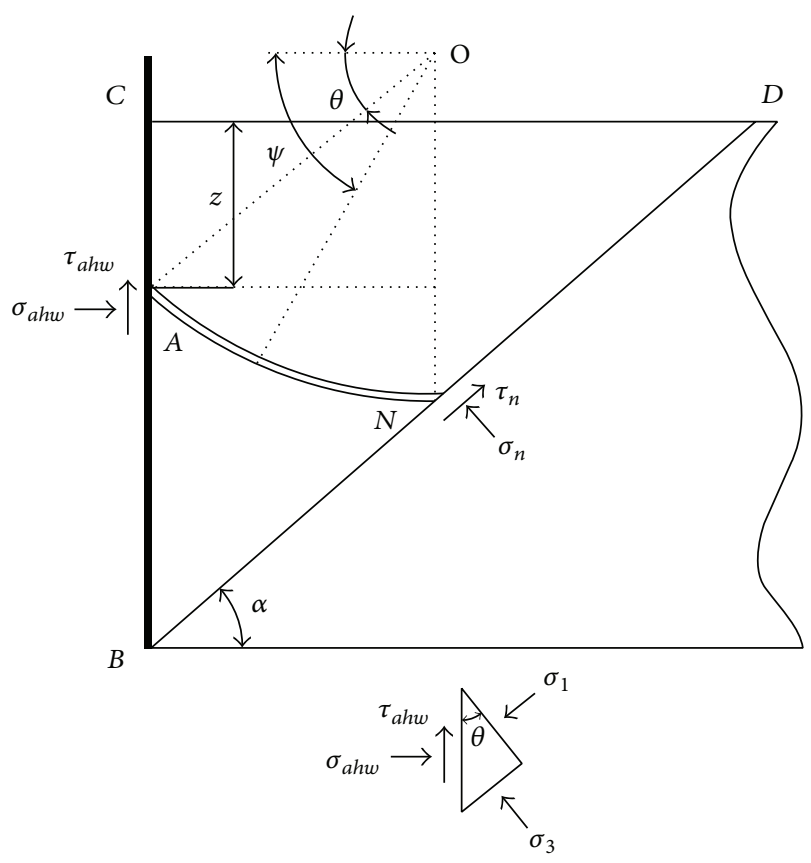

FIGURE 1: Trajectory of minor principal stress.

resistance in soil is just partially mobilized and the friction angle of the soil should be the mean value, $\bar{\phi}$. For the slipping plane in angle of $\alpha$ with the horizontal, it is $\pi / 4+\bar{\phi} / 2$ for active case owing to Rankine theory. With respect to horizontal backfill retained by a perfectly smooth wall, the earth pressure on the wall is the principal stress and the lateral pressure coefficient assumes a well-known expression [24]. Consider

$$
K_{a}=\frac{1}{N}=\frac{\sigma_{3}}{\sigma_{1}}=\tan ^{2}\left(\frac{\pi}{4}-\frac{\bar{\phi}}{2}\right),
$$

where $N$, which can be deduced from Mohr circle, as shown in Figure 2, is

$$
N=\frac{\sigma_{1}}{\sigma_{3}}=\frac{1+\sin \bar{\phi}}{1-\sin \bar{\phi}}=\tan ^{2}\left(\frac{\pi}{4}+\frac{\bar{\phi}}{2}\right) .
$$

However, in field, the direction of the principal stress on the wall is at a slight tilt in view of the wall friction. The arch shown in Figure 1 describes the direction of the minor principal stress in virtue of Handy's theory and also describes the soil enclosed in a region where there are no shearing stresses on the trajectory of the region. It is easy to arrive at a conclusion that the angle between the slip plane and minor principal stress can be $\pi / 4+\bar{\phi} / 2$ from Mohr theory. It then draws the conclusion that the minor principal stress must be horizontally acting on the right edge of the arch. At the left of the arch, the horizontal normal stress on the wall at depth $z$, $\sigma_{a h w}$, can be calculated by considering the force equilibrium in triangular element near the wall, as shown in the bottom of Figure 1. Being equivalent of horizontal normal stress on the wall, the lateral stress can be

$$
\sigma_{a h w}=\sigma_{1} \cos ^{2} \theta+\sigma_{3} \sin ^{2} \theta,
$$




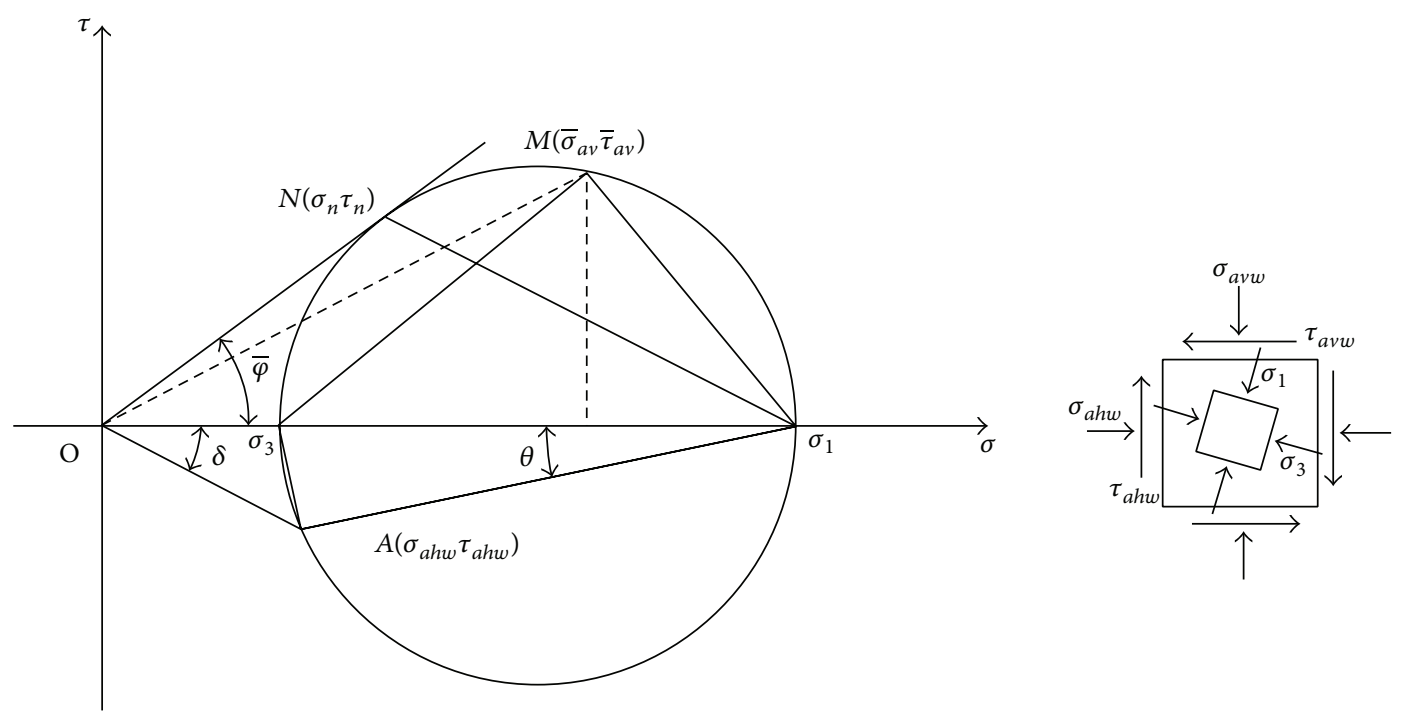

FIGURE 2: Mohr circle for earth stresses near the wall.

where $\theta$ describes the direction of the major principal stress with respect to horizontal near the wall. The conjugate vertical normal stress is expressed by

$$
\sigma_{a v w}=\sigma_{1} \sin ^{2} \theta+\sigma_{3} \cos ^{2} \theta
$$

Similarly, the horizontal normal stress at the random point along the arch with angle $\psi$ to the horizontal can be expressed by

$$
\sigma_{a h}=\sigma_{1} \cos ^{2} \psi+\sigma_{3} \sin ^{2} \psi
$$

The conjugate vertical normal stress is given by

$$
\sigma_{a v}=\sigma_{1} \sin ^{2} \psi+\sigma_{3} \cos ^{2} \psi
$$

Dividing (5) and (6) by $\sigma_{1}$ and substituting $\sigma_{3} / \sigma_{1}=1 / N$ can derive

$$
\begin{aligned}
& \frac{\sigma_{a h}}{\sigma_{1}}=\cos ^{2} \psi+\frac{1}{N} \sin ^{2} \psi, \\
& \frac{\sigma_{a v}}{\sigma_{1}}=\sin ^{2} \psi+\frac{1}{N} \cos ^{2} \psi .
\end{aligned}
$$

Based on the theory of Mohr circle, as shown in Figure 2, the shear stress, $\tau_{a h w}$, on the left edge of the arch is given by

$$
\tau_{a h w}=\sigma_{a h w} \tan \delta=\left(\sigma_{a h w}-\sigma_{3}\right) \tan \theta .
$$

Thus,

$$
\tan \theta=\frac{\sigma_{a h w} \tan \delta}{\sigma_{a h w}-\sigma_{3}}
$$

Substitution of (3) into (9) yields a quadratic equation

$$
\tan \theta=\frac{\left(\sigma_{1} \cos ^{2} \theta+\sigma_{3} \sin ^{2} \theta\right) \tan \delta}{\sigma_{1} \cos ^{2} \theta-\sigma_{3} \cos ^{2} \theta}=\frac{\left(N+\tan ^{2} \theta\right) \tan \delta}{N-1} .
$$

Solving (10) for $\tan \theta$ gives

$$
\tan \theta=\frac{(N-1) \pm \sqrt{(N-1)^{2}-4 N \tan ^{2} \delta}}{2 \tan \delta}
$$

For fear of the error propagation, it is an appropriate methodology to replace $\tan \theta$ by character $k$. Of the two values given by (11), the larger one dovetails nicely with the experiments by Guo and Zhou [28].

The lateral earth pressure coefficient can be defined by the ratio of the horizontal stress to the vertical stress. As for a slice with depth $z$ from the surface of the backfill, the lateral earth pressure coefficient is bound up with the horizontal normal stress and the average vertical normal stress. The vertical normal stress acting on the unit arch, corresponding to the given slice, can be calculated as

$$
\mathrm{d} V=\sigma_{1}\left(\sin ^{2} \psi+\frac{1}{N} \cos ^{2} \psi\right)(R \sin \psi \mathrm{d} \psi)
$$

where $R$ is the radius of the arch, representing minor principal stress trajectory, and it can be given by

$$
R=\frac{H-z}{1-\sin \theta+\cos \theta \tan \alpha} .
$$

The vertical component of average normal stress along the arch can be calculated by

$$
\begin{aligned}
\bar{\sigma}_{a v} & =\frac{\int_{\theta}^{\pi / 2} \mathrm{~d} V}{R \cos \theta}=\int_{\theta}^{\pi / 2} \sigma_{1}\left(\sin ^{2} \psi+\frac{1}{N} \cos ^{2} \psi\right) \frac{\sin \psi}{\cos \theta} \mathrm{d} \psi \\
& =\sigma_{1}\left(1-\frac{N-1}{3 N} \cos ^{2} \theta\right) .
\end{aligned}
$$




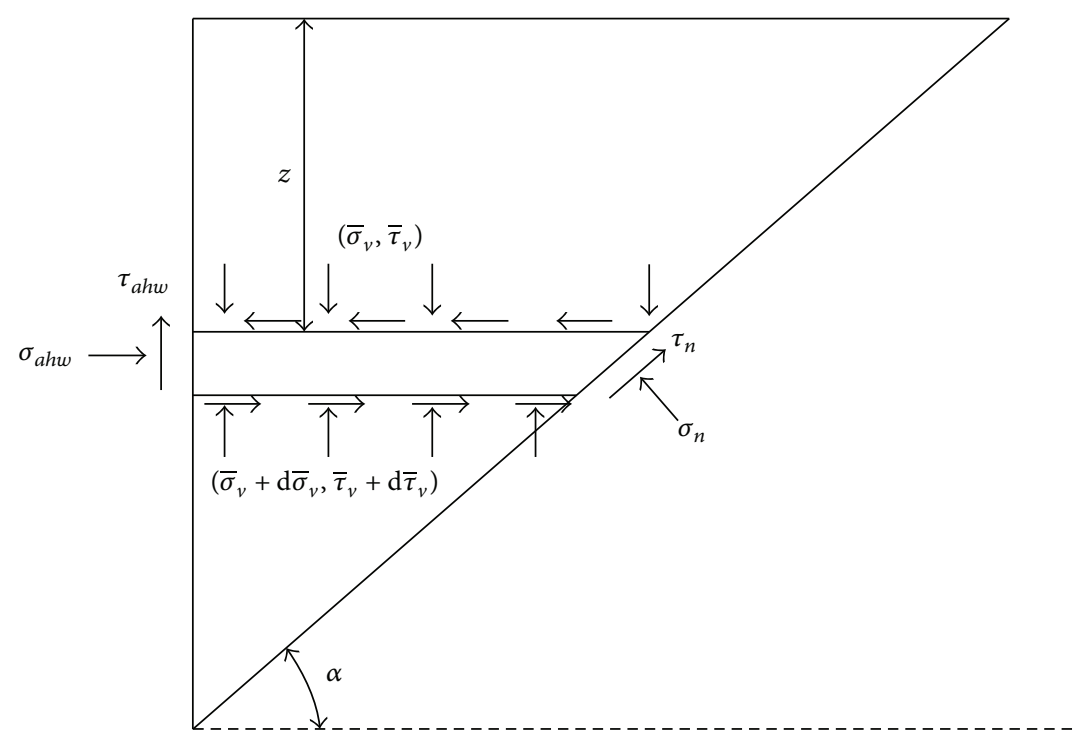

FIGURE 3: Free body diagram of differential slice.

Dividing (1) by (14), it can be derived that

$$
\begin{aligned}
K & =\frac{\sigma_{1} \cos ^{2} \theta+\sigma_{3} \sin ^{2} \theta}{\sigma_{1}\left(1-((N-1) / 3 N) \cos ^{2} \theta\right)}=\frac{3 N \cos ^{2} \theta+3 \sin ^{2} \theta}{3 N-(N-1) \cos ^{2} \theta} \\
& =\frac{3 N+3 k^{2}}{1+2 N+3 N k^{2}} .
\end{aligned}
$$

From (15), it should lay great stress on the fact that the lateral earth pressure coefficient only has relation to the ratio of principal stresses $\left(N=\sigma_{1} / \sigma_{3}\right)$ and the wall-soil friction angle $(\delta)$.

The shear stress, $\bar{\tau}_{a v}$, corresponding to $\bar{\sigma}_{a v}$ can be obtained in the following way. As shown in Mohr circle, it can be deduced from triangular diagram that

$$
\bar{\tau}_{a v}^{2}=\left(\sigma_{1}-\bar{\sigma}_{a v}\right)\left(\bar{\sigma}_{a v}-\sigma_{3}\right)
$$

Substituting (14) in (16), it can be obtained that

$$
\bar{\tau}_{a v}=\frac{1}{3} \sigma_{1} \cos \theta\left(1-\frac{1}{N}\right) \sqrt{3-\cos ^{2} \theta} .
$$

Rather, the coefficient ratios between $\bar{\tau}_{a v}$ and $\bar{\sigma}_{a v}$ are kept as the function of $\theta$ and can be exhibited as

$$
K_{a v}=\frac{(N-1) \cos \theta \sqrt{3-\cos ^{2} \theta}}{3 N-(N-1) \cos ^{2} \theta} .
$$

According to the trigonometric function, (18) can be transformed into

$$
K_{a v}=\frac{(N-1) \sqrt{2+3 k^{2}}}{1+2 N+3 N k^{2}}
$$

\section{Analysis of Earth Pressure on the Retaining Wall of RB}

The differential slice technique is widely applied for the limit equilibrium condition where an active horizontal displacement of sliding wedge has developed in the soil mass behind a retaining wall. The technique has not been used for valid distribution of lateral earth pressures which is necessary in the design of walls in which the shearing resistance of the soil mass behind the wall is not completely mobilized according to rotation and earth arching effects. Based on the differential slice technique, the following is to discuss the earth pressure, resultant earth force, and its location of application on the retaining wall rotating about base considering arching effects. At all events, friction always serves itself as a force that opposes motion. Distinguished from differential slice technique for translation mode, it should take into account friction forces between slices for RB mode. Figure 3 shows local force equilibrium of differential slice at the depth $z$ from the surface of the backfill behind the rotating wall. $\sigma_{a h w}$ is the horizontal components acting by retaining wall; $\tau_{a h w}$ is the vertical components caused by friction between the wall and the soils; $\bar{\sigma}_{v}$ and $\bar{\tau}_{v}$ represent the mean vertical normal stress and the mean shear stress acting on the top, respectively; $\bar{\sigma}_{v}+\mathrm{d} \bar{\sigma}_{v}$ and $\bar{\tau}_{v}+\mathrm{d} \bar{\tau}_{v}$ represent the mean vertical normal stress and the mean shear stress acting on the bottom, respectively; $\sigma_{n}$ and $\tau_{n}$ represent the normal stress and the shear stress acting on the slipping surface, respectively; $\alpha$ is the angle of slipping surface respecting the horizontal; $d W$ is the weight of the differential slice; $\gamma$ is the bulk density of the soil. The equilibrium of force for horizontal can be expressed as

$$
\begin{aligned}
& \sigma_{a h w} \mathrm{~d} z+\tau_{n} \frac{\mathrm{d} z}{\sin \alpha} \cos \alpha-\sigma_{n} \frac{\mathrm{d} z}{\sin \alpha} \sin \alpha-\bar{\tau}_{v}(H-z) \cot \alpha \\
& +\left(\bar{\tau}_{v}+\mathrm{d} \bar{\tau}_{v}\right)(H-z-\mathrm{d} z) \cot \alpha=0 .
\end{aligned}
$$


After elided quadratic differential item, (20) is simplified:

$$
\begin{aligned}
& \sigma_{a h w} \mathrm{~d} z+\tau_{n} \cot \alpha \mathrm{d} z-\sigma_{n} \mathrm{~d} z+(H-z) \cot \alpha \mathrm{d} \bar{\tau}_{v}-\bar{\tau}_{v} \cot \alpha \mathrm{d} z \\
& \quad=0 .
\end{aligned}
$$

Summation of all forces in vertical acting on the differential slice yields

$$
\begin{gathered}
\mathrm{d} \bar{\sigma}_{v}(H-z) \cot \alpha+\tau_{a h w} \mathrm{~d} z+\sigma_{n} \mathrm{~d} z \cot \alpha+\tau_{n} \mathrm{~d} z \\
-\bar{\sigma}_{v} \mathrm{~d} z \cot \alpha-\mathrm{d} W=0 .
\end{gathered}
$$

Because of the overt relationship between normal stresses and shear stresses along the wall and along the slipping surface, it is liable to reach the following expressions:

$$
\begin{aligned}
\sigma_{a h w} & =K \bar{\sigma}_{v}, \\
\tau_{n} & =\sigma_{n} \tan \phi, \\
\tau_{a h w} & =\sigma_{a h w} \tan \delta, \\
\bar{\tau}_{v} & =K_{a v} \bar{\sigma}_{v}, \\
\mathrm{~d} W & =\gamma(H-z) \cot \alpha \mathrm{d} z .
\end{aligned}
$$

Substituting (23) into (21) and (22), the yielded simultaneous equations could be reduced as

$$
\frac{\mathrm{d} \bar{\sigma}_{v}}{\mathrm{~d} z}=A \gamma-\frac{(1-B K) \bar{\sigma}_{v}}{H-z}
$$

where

$$
\begin{aligned}
A & =\frac{(1-\tan \phi \cot \alpha)}{C}, \\
B & =\frac{(1+\tan \alpha \tan \phi+\tan \delta \tan \alpha-\tan \delta \tan \phi)}{C}, \\
C & =1+\cot \alpha\left(K_{a v}-\tan \phi\right)+K_{a v} \tan \phi .
\end{aligned}
$$

Further, it should be emphasized that the stress integration in (24) over the height must be in accordance with initial condition of $\bar{\sigma}_{v}=0$ at $z=0$. Thus, $\bar{\sigma}_{v}$ can be expressed as

$$
\bar{\sigma}_{v}=\frac{A H \gamma}{B K-2}\left(\left(1-\frac{z}{H}\right)-\left(1-\frac{z}{H}\right)^{B K-1}\right) .
$$

The horizontal lateral pressure can be got with a given lateral pressure coefficient

$$
\sigma_{a h w}=K \bar{\sigma}_{v}=\frac{K A \gamma H\left((1-(z / H))-(1-(z / H))^{B K-1}\right)}{B K-2}
$$

and then the horizontal component of the resultant force can be the integration of (27):

$$
\begin{aligned}
F_{h} & =\int_{0}^{H} \frac{K A \gamma H\left((1-(z / H))-(1-(z / H))^{B K-1}\right)}{B K-2} \mathrm{~d} z \\
& =\frac{A \gamma H^{2}}{2 B K} .
\end{aligned}
$$

As shown in Figure 1, the total resultant thrust can be calculated as

$$
F_{T}=\frac{F_{h}}{\cos \delta}=\frac{A \gamma H^{2}}{(4-2 B K) \cos \delta} .
$$

The application point of the total force is the focus in engineering practice. For the distribution of lateral earth pressure is nonlinear, the height of application of the earth force on the wall can be obtained by dividing the moment of the lateral earth pressure about the base by the lateral horizontal earth force. The moment, $M$, can be the integral of moment of slices about the base

$$
\begin{aligned}
M & =\int_{0}^{H} \frac{K A \gamma H\left((1-(z / H))^{1-B K}-(1-(z / H))\right)}{B K}(H-z) \mathrm{d} z \\
& =\frac{K A \gamma H^{3}}{3+3 B K}
\end{aligned}
$$

and the location of application of the total earth force is expressed as

$$
l=\frac{M}{F_{h}}=\frac{2 B K H}{3+3 B K} .
$$

\section{Results and Discussion}

Results of observation from Fang and Ishibashi [13] model studies furnish the basis for the present discussions. The tests involved a $1 \mathrm{~m}$ high wall rotating about the base in a loose to medium dense sand $\left(\bar{\phi}=33.4^{\circ} \rightarrow 40.4^{\circ}\right.$ and $\gamma=15.4 \mathrm{kN} / \mathrm{m}^{3}$ ). The limiting value of wall friction $\delta$ is always treated as a linear function of internal friction $\bar{\phi}$ and expressed as $\delta=a \bar{\phi}$. With respect to two cases discussed here, it can conservatively replace $\delta$ by $\delta=2 \bar{\phi} / 3$. Figure 4 plots the calculated values of the point of application of the active thrust with respect to the soil shear strength. The results indicate that the arching effects bring about higher location of active resultant forces than those without considering arching effects behind walls rotating about the base. The comparison also reveals that only small differences exist between the results with arching effects and the measured datum.

Figure 5 shows a comparison of calculated lateral pressures with Fang's measurements [13] for the case of RB in sand $\left(\bar{\phi}=33.4^{\circ}\right)$. Such comparison is also done with Rankine theory [2] and Choudhury theory [7] as shown in Figure 5. This case is viewed as quasi-active state for the shearing resistance at the base becoming fully mobilized [15]. The curve, plotted as the normalized mobilized lateral pressure in equilibrium state, $\sigma_{v} / \gamma H$, versus the normalized depth, $z / H$, clearly shows the nonlinear lateral earth pressure distribution. The trajectory agrees with the experimental data by Fang and Ishibashi and the calculated resultant force is about only $2.64 \%$ less than the active Rankine value but has some difference with Choudhury theory [7].

Prior to rotation, the stress state in the soil will correspond to the initial at-rest condition as naturally deposited sand. 


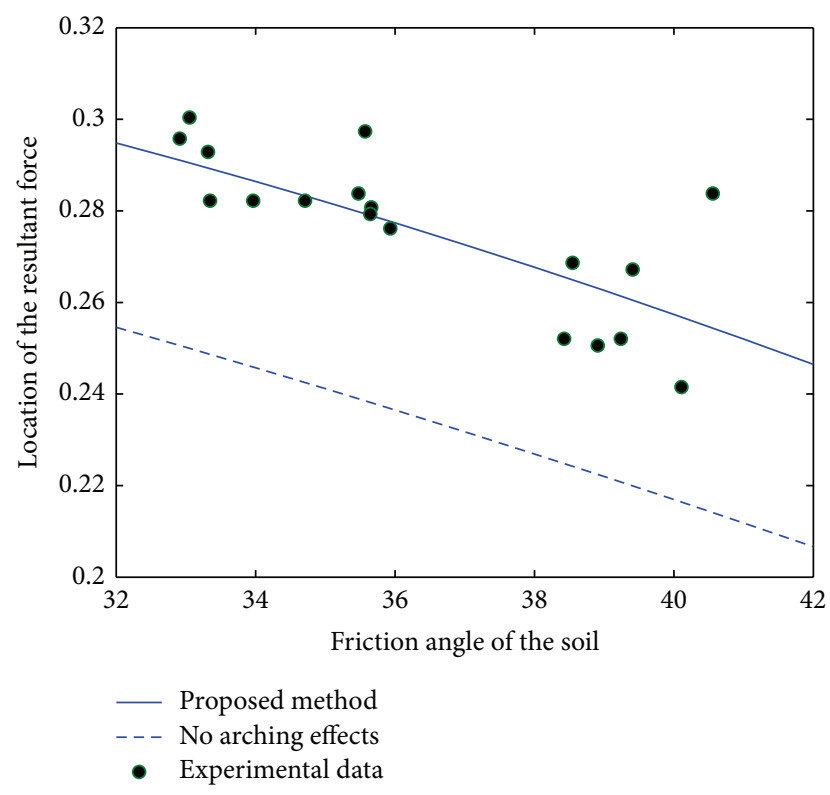

FIGURE 4: Effect of $\bar{\phi}$ on normalized height of application of thrust.

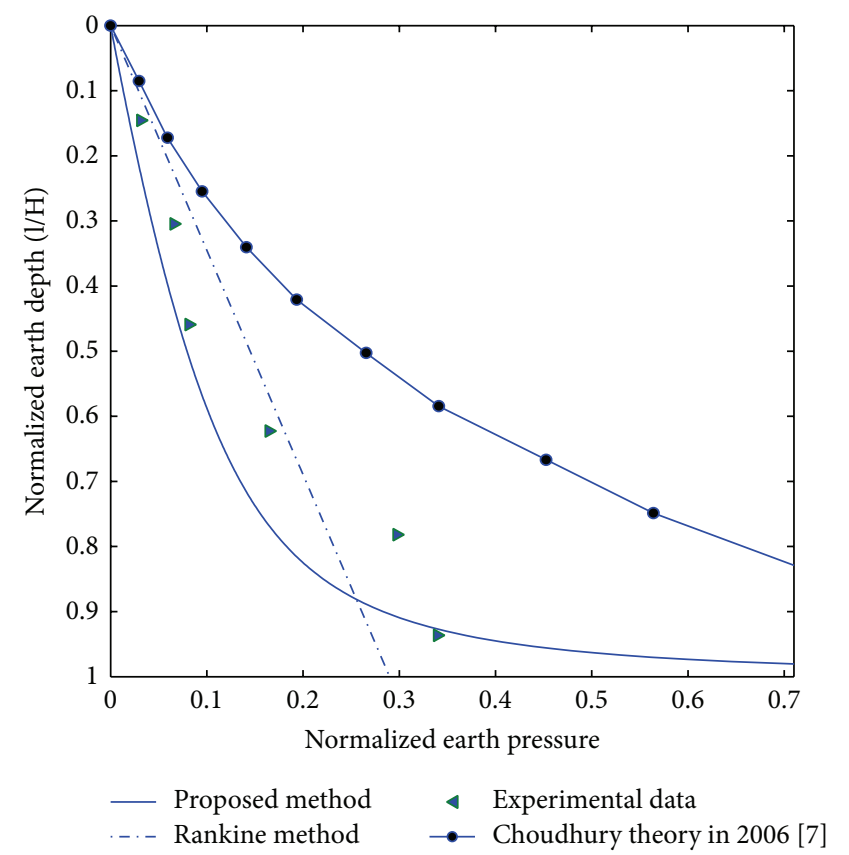

FIGURE 5: Distribution of normalized earth pressure with different methods for the case $\bar{\phi}=33.4^{\circ}$.

In virtue of that mobilization of shearing resistance will propagate downwards as the angle of rotation increases [29]; it should select a proper initial angle of internal friction of the soil for at-rest condition. As method of Chang's model [15], the following case chooses $\phi_{0}=10.4^{\circ}$ for $\bar{\phi}=33.4^{\circ}$. Figure 6 shows a similar comparison between several analytical methods and experimental results for $\mathrm{RB}$ in conformity to partially mobilized sand $\left(\phi_{0}=10.4^{\circ}\right)$. The comparisons exhibit that the present method fits the

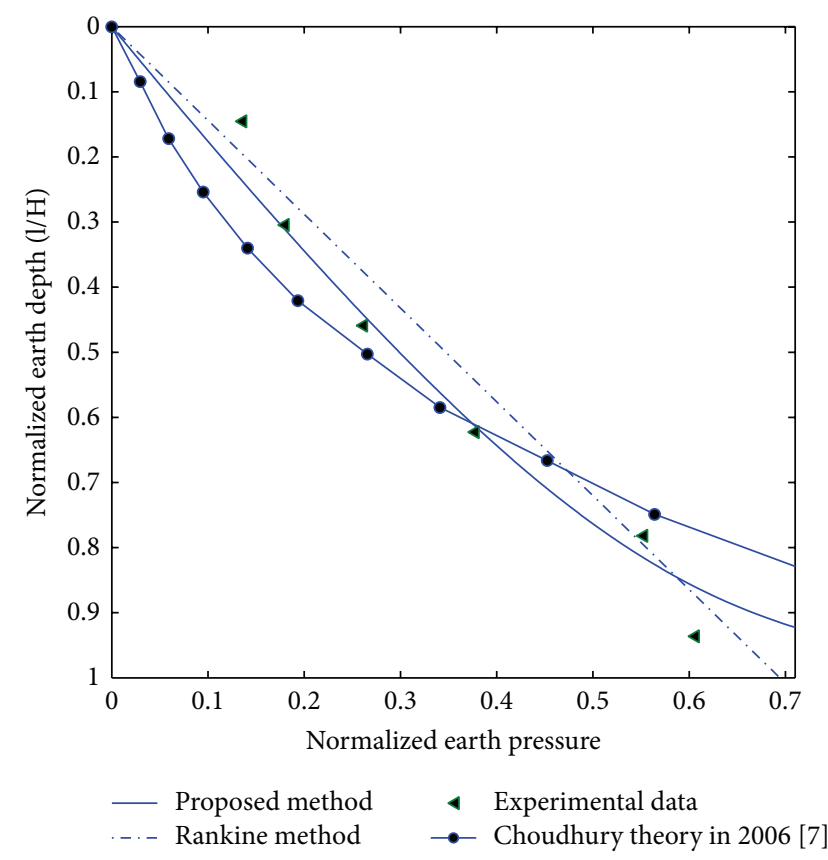

FIGURE 6: Distribution of normalized earth pressure with different methods for the case $\phi_{0}=10.4^{\circ}$.

experiment datum better than Choudhury's theory [7]. It is also revealed that the calculated pressure on the wall is only slightly deviated from the experimental data and that the calculated resultant force is only $2.33 \%$ less than result of Rankine method.

\section{Conclusion}

An analytical method has been developed for the calculation of lateral earth pressure on the wall rotating about base considering arching effects in the backfill. The method uses differential slice technique and incorporates the deformation of stress distribution according to arching effects in the soil. Results calculated using lateral pressure coefficient that properly reflects the arching effects agree well with the model test data for backfilled walls rotating about the base. The following conclusions can also be drawn from aforementioned process.

(1) For a rotating wall about the base, an analytical method of shear stresses in slices is proposed in base of Mohr circle theory. It is simply exhibited as product of a scale coefficient with normal stress in horizontal slices.

(2) In the light of proposed method, the resultant lateral soil thrust exerted against the rotating wall about the base is less by only about $2.68 \%$ than the values estimated by the Rankine equation for fully mobilized case and by only about $2.35 \%$ for initial mobilized case. In contrast to single value of $\mathrm{H} / 3$ with Rankine theory, the variable point of application of the resultant force calculated by proposed method matches the experimental results which are higher than the value calculated by method without arching effects. 
(3) As shown in comparison with Fang's experiment, the proposed method can reflect the nonlinear distribution of earth pressure on the wall and is identical to the datum of experiments.

Although the method developed here is primarily for cohesionless soil, the concept of the analysis and similar equations could be developed for soil with cohesion. Analysis for the passive case using this approach and the movement mode of the wall can be further discussed based on this work.

\section{Conflict of Interests}

The authors declare that there is no conflict of interests regarding the publication of this paper.

\section{Acknowledgment}

This work was supported by the Tianjin Research Program of Application Foundation and Advanced Technology under Grant no. 12JCZDJC28000. This support is greatly appreciated.

\section{References}

[1] C. A. Coulomb, Essai Sur une Application des règles de Maximis et Minimis à quelques Problèmes de Statique Relatifs à l'architecture, De l'Imprimerie Royale, 1776.

[2] W. M. Rankine, On the Stability of Loose Earth, Philosophical Transactions of the Royal Society of London, 1857.

[3] M. Khajehzadeh, M. R. Taha, A. El-Shafie, and M. Eslami, "Modified particle swarm optimization for optimum design of spread footing and retaining wall," Journal of Zhejiang University: Science A, vol. 12, no. 6, pp. 415-427, 2011.

[4] R. Xu, "The GA-ANN method for determining calculation parameters for deep excavation," Journal of Zhejiang University Science A, vol. 1, no. 4, pp. 408-413, 2000.

[5] Y.-Z. Wang, "Distribution of earth pressure on a retaining wall," Geotechnique, vol. 50, no. 1, pp. 83-88, 2000.

[6] K. Terzaghi, Theoretical Soil Mechanics, John Wiley \& Sons, New York, NY, USA, 1943.

[7] D. Choudhury and S. Chatterjee, "Displacement-based seismic active earth pressure on rigid retaining walls," Electronic Journal of Geotechnical Engineering, vol. 11, 2006.

[8] D. Choudhury and S. Chatterjee, "Dynamic active earth pressure on retaining structures," Sadhana, vol. 31, no. 6, pp. 721$730,2006$.

[9] D. Choudhury and S. S. Nimbalkar, "Pseudo-dynamic approach of seismic active earth pressure behind retaining wall," Geotechnical and Geological Engineering, vol. 24, no. 5, pp. 1103-1113, 2006.

[10] K. S. S. Rao, S. Nayak, and D. Choudhury, "Determination of displacement-related passive earth pressure," Geotechnical Engineering, vol. 35, no. 2, pp. 79-85, 2004.

[11] R. G. James and P. L. Bransby, "Experimental and theoretical investigations of a passive earth pressure problem," Géotechnique, vol. 20, no. 1, pp. 17-37, 1970.

[12] M. A. Sherif, I. Ishibashi, and C. D. Lee, "Earth pressures against rigid retaining walls," Journal of the Geotechnical Engineering Division, vol. 108, no. 5, pp. 679-695, 1982.
[13] Y.-S. Fang and I. Ishibashi, "Static earth pressures with various wall movements," Journal of Geotechnical Engineering, vol. 112, no. 3, pp. 317-333, 1986.

[14] M. Matsuo, S. Kenmochi, and H. Yagi, "Experimental study on earth pressure of retaining wall by field tests," Soils and Foundations, vol. 18, no. 3, pp. 27-41, 1978.

[15] M. F. Chang, "Lateral earth pressures behind rotating walls," Canadian Geotechnical Journal, vol. 34, no. 4, pp. 498-509, 1997.

[16] F. Song and J.-M. Zhang, "Estimation of seismic earth pressures against rigid retaining structures with rotation mode," Open Civil Engineering Journal, vol. 5, no. 1, pp. 52-60, 2011.

[17] B. Chevalier, G. Combe, and P. Villard, "Experimental and numerical study of the response of granular layer in the trap-door problem," in Powders and Grains, AIP Conference Proceedings, p. 649, July 2009.

[18] B. Chevalier, G. Combe, and P. Villard, "Experimental and discrete element modeling studies of the trapdoor problem: influence of the macro-mechanical frictional parameters," Acta Geotechnica, vol. 7, no. 1, pp. 15-39, 2012.

[19] K. Deb, "A mathematical model to study the soil arching effect in stone column-supported embankment resting on soft foundation soil," Applied Mathematical Modelling, vol. 34, no. 12, pp. 3871-3883, 2010.

[20] T. Eskișar, J. Otani, and J. Hironaka, "Visualization of soil arching on reinforced embankment with rigid pile foundation using X-ray CT,' Geotextiles and Geomembranes, vol. 32, pp. 4454, 2012.

[21] K. Terzaghi, Soil Mechanics in Engineering Practice, John Wiley \& Sons, New York, NY, USA, 1996.

[22] R. L. Handy, "The arch in soil arching," Journal of Geotechnical Engineering, vol. 111, no. 3, pp. 302-318, 1985.

[23] K. Harrop-Williams, "Arch in soil arching," Journal of Geotechnical Engineering, vol. 115, no. 3, pp. 415-419, 1989.

[24] K. H. Paik and R. Salgado, "Estimation of active earth pressure against rigid retaining walls considering arching effects," Geotechnique, vol. 53, no. 7, pp. 643-653, 2003.

[25] B. Jiang, H.-W. Ying, and K.-H. Xie, "Analysis on soil arching behind retaining wall," Journal of Zhejiang University (Engineering Science), vol. 39, no. 1, pp. 131-136, 2005.

[26] V. Potts and L. Zdravkovic, "Finite element analysis of arching behaviour in soils," in Proceedings of the 12th International Conference on Computer Methods and Advances in Geomechanics, pp. 3642-3649, October 2008.

[27] S. S. Nadukuru and R. L. Michalowski, "Arching in distribution of active load on retaining walls," Journal of Geotechnical and Geoenvironmental Engineering, vol. 138, no. 5, pp. 575-584, 2012.

[28] P. Guo and S. Zhou, "Arch in granular materials as a free surface problem," International Journal for Numerical and Analytical Methods in Geomechanics, 2012.

[29] H. Matsuzawa and H. Hazarika, "Analyses of active earth pressure against rigid retaining wall subjected to different modes of movement," Soils and Foundations, vol. 36, no. 3, pp. 51-65, 1996. 


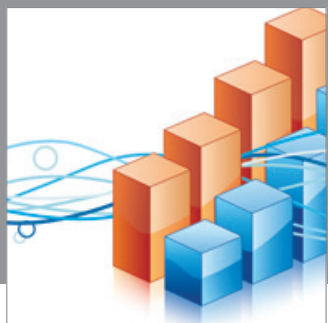

Advances in

Operations Research

mansans

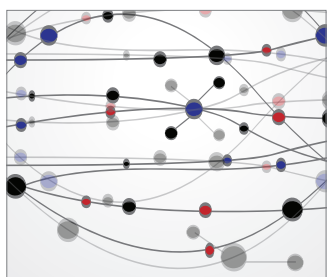

The Scientific World Journal
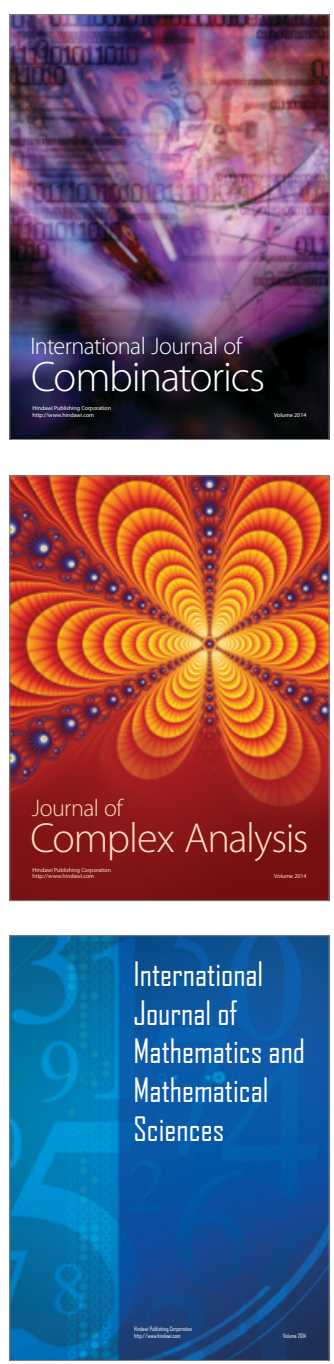
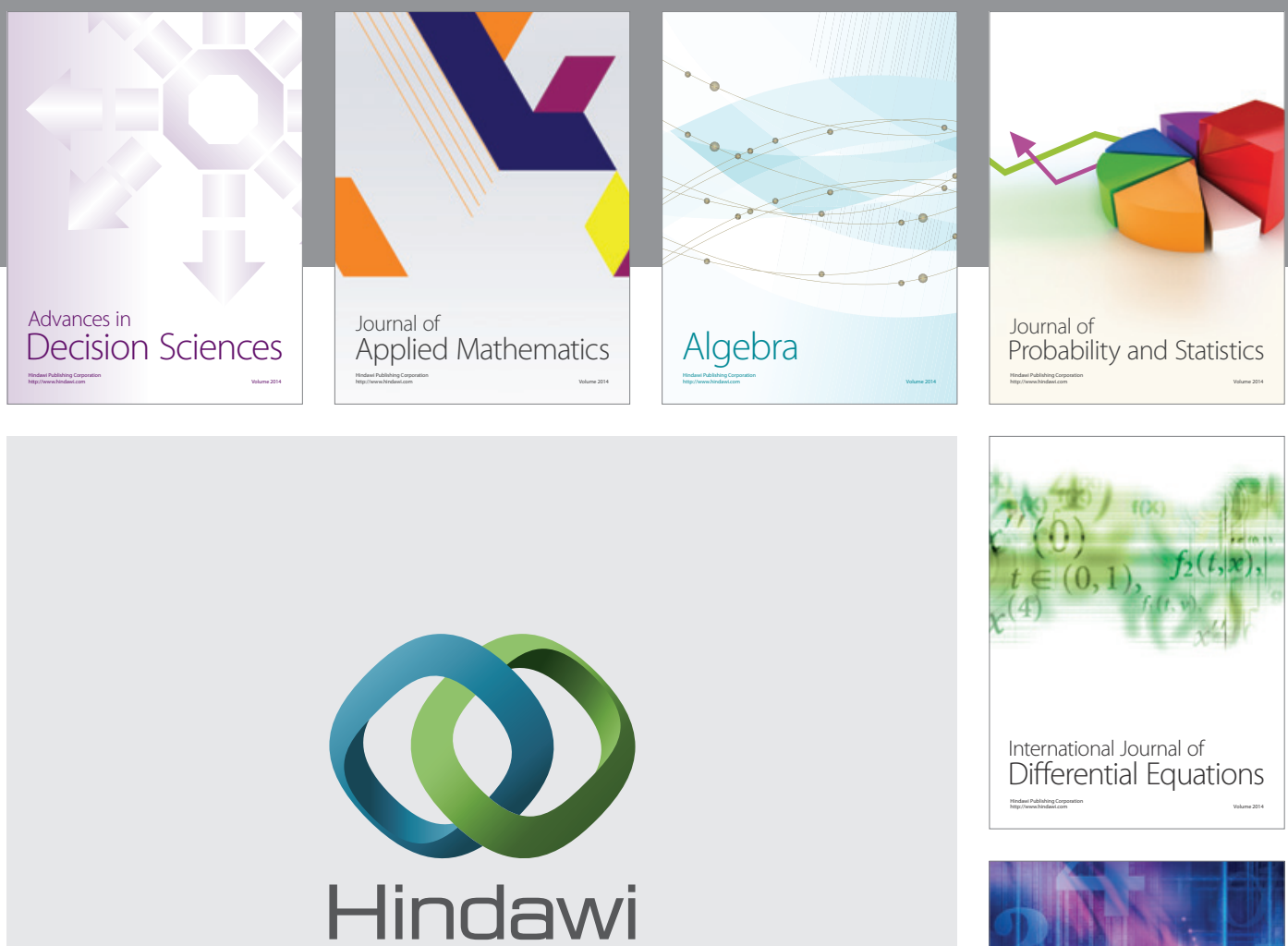

Submit your manuscripts at http://www.hindawi.com
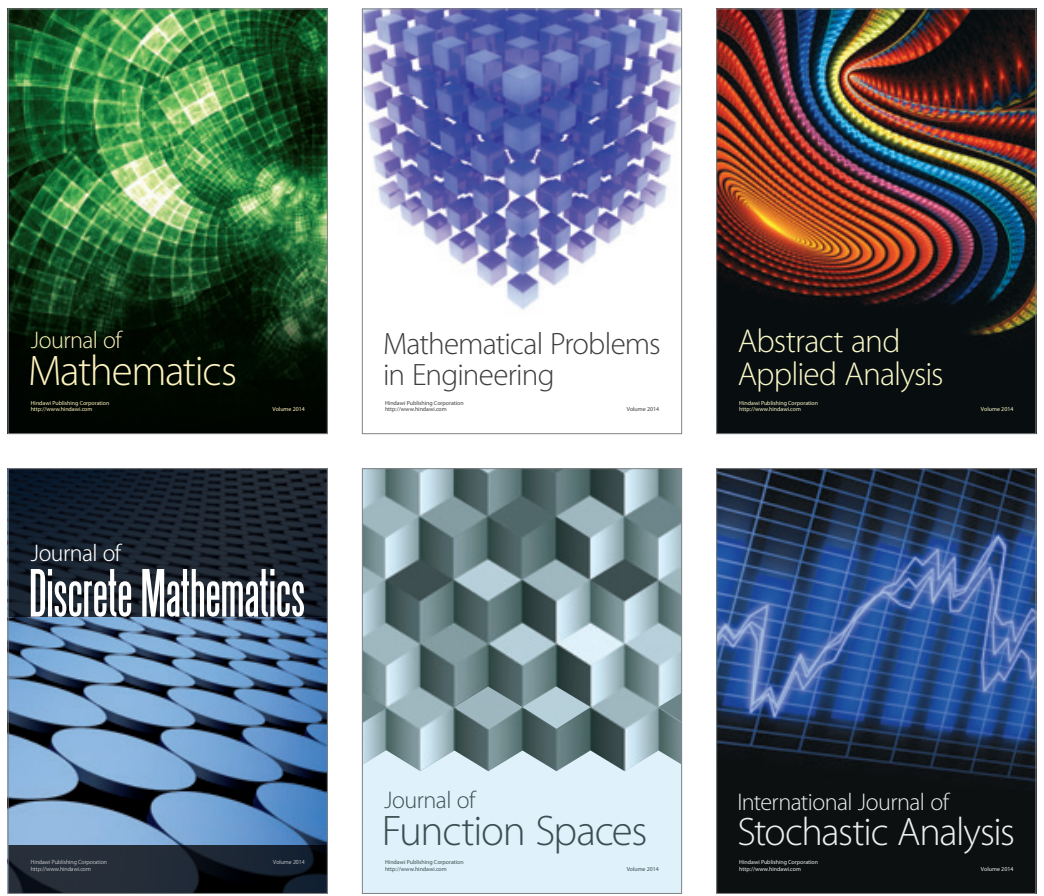

Journal of

Function Spaces

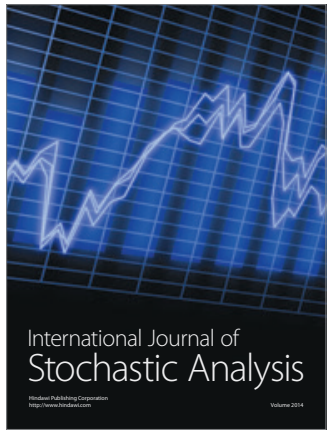

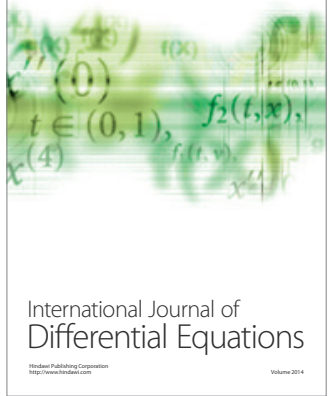
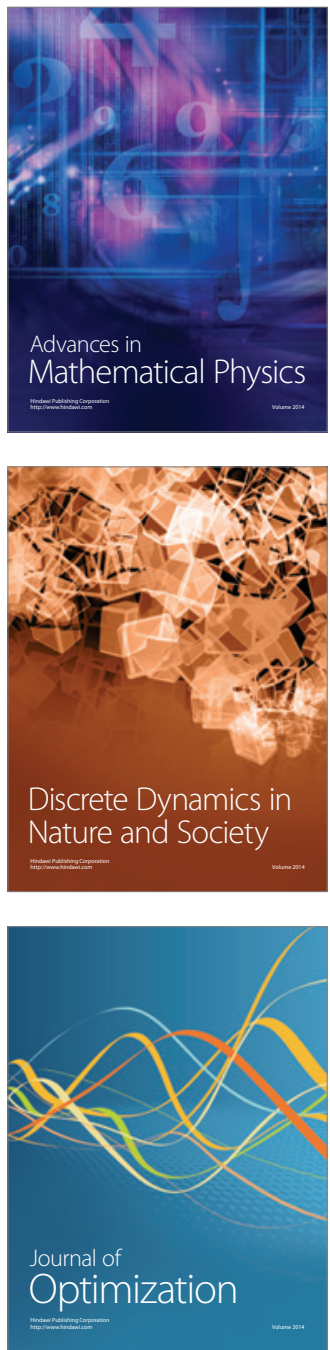